\title{
The Sentient Spoon as broken puppet: Celebrating otherness with performing objects
}

Matt Smith

University of Portsmouth

Dr Matt Smith is a senior lecturer in Applied Theatre at the University of Portsmouth, UK. Matt has twenty-five years' experience working in diverse settings such as schools, prisons, environmental agencies, arts for health, youth arts, disability arts groups and with the homeless. Matt's practice is interdisciplinary mixing drama, puppetry, masks and junk music.

Contact: School of Art, Design and Performance, University of Portsmouth, White Swan Building, White Swan Road, Portsmouth, PO1 2GA, UK.

E-mail: matt.smith@port.ac.uk

https://orcid.org/0000-0002-2570-0594

Received 3 April 2020; Accepted 13 April 2020 


\begin{abstract}
Exploring speculations about new materialism and performance, this article explores how do we (re)consider the 'puppet other' as a subject in community performance, focusing particularly on work with youth who have severe and complex learning difficulties. The discussion of this project explores the ethics and politics of my practice and applied puppetry (Smith 2014) through reflections about the use of puppets and objects in relation to specific communities and identities. The method employed in this article is to explore the world of objects in practice, using the ideas of object-oriented ontology through which to view the poetic process of speculating about the inner reality of objects, in relation to human participants. This exploration of the materiality of objects is framed in reaction to the way power operates, specifically through the Foucauldian lens of biopower.
\end{abstract}

\title{
Keywords
}

object-oriented ontology; disability; transgression; applied theatre; new materialism; embodiment; inclusivity; ethics 


\section{Introduction}

Figures 1 and 2: Sentient Spoon puppet, originally from The Generosity of Penguins (1995) by Lavinia Murray, 2019. Photography by Matt Smith.

The inner language of the puppet remains a mystery, absence and lacuna in my practice. Even when faced with its impossibility, speculations about this imaginative space offer me potential creative sources as an artist and thinker. In this ludic space, I actively and theatrically imagine consciousnesses and voices, and then speculations about materiality open a creative route for my knowledge. These contemplations about the inner life of objects as participants are a method to appreciate the autonomy of an object as thing that Jane Bennett (2009) describes as 'vibrant matter'. These ideas about the inner language and vibrancy of objects inspired me to write the following monologue, for 2018 The Broken Puppet 2 symposium on 'Puppetry and Disability Performance' at Bath Spa University, UK.

Spoony Monologue $\quad$ SENTIENT SPOON: I am a sentient spoon and I also played the part of the Sentient Spoon in the play by Lavinia Murray called The Generosity of Penguins [Pickleherring Theatre touring production 1995]. In this show I played the part of a passenger on the bus driven by the bear Penguin O Maley. In this performance I played opposite a Parrot who played the part of my girlfriend. Unfortunately I was rather upstaged by an adolescent elephant boy. Overall my presence was rather disappointing in this performance because of the issue of my theatrical size.

I was replaced in this performance by a larger spoon who, quite frankly was much simpler in construction and had none of the stylish elegance you can see in my attire. Over the years I have suffered a number of challenges to my form. I lost one of my beady eyes many years ago even though you wouldn’t notice onstage as I am too small. My 
foamy hands have continued to corrupt over the years so I am now missing a number of fingers.

One of the more interesting and personally fulfilling changes has been the breaking of the steel rod to my spoon head even after a number of reconstruction efforts with epoxy and araldite fixatives. After this catastrophic breakdown in my manipulation system the strings were cut to my hands and knees. To be quite honest I have found this change rather liberating and joyful as the steel rod to my head was more than tiresome and the way the strings moved my arms and legs made me look like a substandard thunderbird character.

So, now as a slightly decrepit remain, from a performance that did not rank at the BAFTAS [British Academy of Film and Television Arts] I stand here, as an object that can satisfy your ruin lust. I am small enough to be cute and not too uncanny, as I look back at you with my one beady eye. I prefer the honesty and touch of the direct grasp of the puppeteer moving me, as convincingly as his imagination can muster.

In workshops I may come out and some students will have a fiddle with me and try and understand how to perform with a material other. I haven't stopped being, even now that I am broken. My brokenness has made me 'thinglier' and has brought attention to the alien world of object otherness you all desperately would like to understand but can only speculate about. My otherness is not just one sided, because your brain tries to mirror and imagine a way of inhabiting my shoes. When you look at me you want to be as remarkably other like me. You just slightly want to be a Sentient Spoon. You want to dress as cool as me in my natty jumper, polyester slacks and old school Adidas trainers. If you had my beady eye you could maybe look at objects and recognise their alien phenomenology.

I am tired now but would love to meet you in the bar for a chat afterwards. I don't drink. I guess that is blatantly obvious. I will leave Matt to discuss things in more detail. Thank you. 
As puppeteer and researcher, this speculation about the vibrancy and inner world of the puppet is one method I employ to imagine the puppet's potential life, as in the monologue above. As Spoony the puppet states, he was built for a purpose, but when he no longer functioned in this role, his life did not end, he still existed and remained. Rebecca Schneider (2003) has theorized the issue of performance remains and how this challenges our assumptions about how performance temporally exists. Her point is that performances do not end or disappear when the curtain falls but instead lives on in memories, artefacts and ephemera. Drawing from Schneider, the puppet that is left after a show presents an interesting and vibrant form of performance 'remain'. Through this speculative and embodied practice of considering the inner life of puppets like Spoony, I attempt the impossible navigation into understanding the poetry of objects after performances. The puppeteer Eric Bass (2014) similarly emphasizes the approach by the puppeteer to enter into this visionary space and appreciate the inner poetry of the puppet:

As puppeteers, it is, surprisingly, not our job to impose our intent on the puppet. It is our job to discover what the puppet can do and what it seems to want to do. It has propensities. We want to find out what they are, and support them. We are, in this sense, less like tyrants, and more like nurses to these objects. How can we help them? They are built for a purpose. They seem to have destinies. We want to help them arrive at those destinies.

The issue of how the puppeteer coexists presented by Bass emphasizes the puppeteer as 'nursemaid' in the landscape of performance practice. These problems of co-presence extend beyond the relationship between the object and the performer and into the relationships of other objects and bodies present in the space of practice. The 'propensities' of the performing object as described by Bass as part of the inner language 
of the object is what the puppeteer often seeks out in their craft. Through a practical workshop in 2015, 'Living in the Puppet's World' at Little Angel Theatre, London, with Eric Bass and Ines Zeller Bass, I experienced this developed awareness of the object, and, during this workshop, this notion of feeling through the puppet was central to the approach to practice, described and enacted by Bass.

\section{The propensities of applied puppetry: Theoretical positions}

In my definition of applied puppetry, I argue that the facilitator is attempting to understand the propensities of all participants, whether they are objects or people (Smith 2014). This practice of applied puppetry is a dynamic interplay between ethics, bodies and power that can be found within the context of specific communities (2014: 83). This practice has to consider the power of performing objects in relation to bodies, identities and structural contexts. I situate this practice not just within the frame of performance but also in workshop spaces (2014: 92) and within the vibrant material remains left after shows and performances. The ideal of this practice can be employed as a method to enable groups when making their own performances, which then potentially gives groups and individuals a space through which to represent and discuss concerns and narratives (Smith 2012: 82). This viewpoint, about the propensities of objects, has led me to reconsider the puppet in theory and practice. In this reconsideration, I refer to objectoriented ontology (OOO) and use this theory to encounter the puppet anew. The works of philosopher Graham Harman (2010), video games theorist Ian Bogost (2012) and political theorist Jane Bennett (2009) are important reference points in developing this new viewpoint of objects, and their ideas are applied to the practice when I consider the object in applied puppetry. This set of theories influences speculations about the puppet 
as a form of collaborator in practice. By exploring this method, I set out to explain how I think through the puppet in practice. The vibrant object reconsidered through practice in this way troubles the practitioner role and the participant's location as positioned equally within networks of actants (Latour 1993). Perhaps the object in this context changes more aspects within the network of experience than we like to assume.

Puppet monologues like Spoony's above are inspired by engaging with the theories associated with new materialism developed by the philosopher Graham Harman (2010). The implications of his thought and the movement in contemporary critical thinking that is OOO offers potential insights into the world of objecthood but also challenges the practitioner of object and puppet theatre to re-examine their practices.

The puppetry workshop becomes the laboratory for exploring the contours of objects in practice. This notion is developed through Harman's conceptual frame of the object displaying a great deal more about itself and about human participants as agents. Using the speculative approach, I project myself into the imagined consciousness of the object or puppet and speculate about what is there. This viewpoint is both a humbling and stimulating activity in relation to conceptualizing reality and relations between objects and states of being. In the experience of practice, ways of understanding this dynamic are enacted through appreciation of the way objects, space and time interact. Speculating about what is left within this vibrant matter of these puppets is a technique in which to make sense of the way networks of objects or things exist and are expressed in unique spaces.

In relation to theories that influence my view of practice using OOO, Bogost in Alien Phenomenology (2012) presents an engaging heuristic with which to interpret the 
power of performing objects as a practice. This is particularly the case when the puppet artist is exploiting the potential of the object and presenting it with increased agency. Bogost's method opens up a new way to view experiences of the 'otherness' of objects when they are performed and brought into particular networks. The metaphorical and phenomenological practice that Bogost suggests has also influenced the way that I reflected on and subsequently relate to objects involved within the geographies of applied puppetry. In relation to the puppet's imagined agency, my viewpoint about the status of the puppet means these puppet figures become collaborators in developing knowledge. The puppet's experience of the practice and research has become an important aspect and 'alien' viewpoint to consider and to explore from both inside and outside the spaces I experience. The alien experience of the puppet when brought into social networks highlights perspectives about the concept of what it is to be both 'alien' and 'other'. In this way, the puppet can be considered both at home and out of place in the networks and units of objects in workshops and community performances.

This othering was very pronounced when I conducted puppet workshops and performances in an Immigration Removal Centre (2014-16), as the men I worked with were trapped there; they were also made alien and other by the harsh inhumane biopolitical processing of their bodies as part of border controls. In this hideous context, the puppets' 'otherness' was present, but also its potential as 'other' enabled some very unusual interactions between incarcerated bodies, performing objects and myself as artist (Smith 2018).

Relating this experience of practice to OOO drawn into this viewpoint of applied puppetry suggests a flattening out of the relationship of humans to non-human things. 
This horizontal relationship between objects and subjects is controversial because the flattening out of material and bodies also happens as part of the dehumanizing of people who are othered or marginalized. This flattening has occurred in the imaginative space of practice in the way I employ the puppet to speak about its experience, but the intention is to increase the status of the object in relation to the human body. The intention, to give the object more significance on a higher level, brings the object towards the already high status of the participant in workshops and does not lessen any particular actant's power. This interaction of actants within the space of practice was well represented within an unusual intervention within public space to be discussed below.

\section{Cultural Olympiad puppets: Practical case study discussion}

As part of a national lottery-funded project, within the Cultural Olympiad in 2010 (cultural events leading towards the Olympics), I led a collaborative project with the Marie Rose Academy special school in Portsmouth (that has great pride in its sporting activities), creating 'sporting giants' in the form of large-scale street puppets with pupils who have severe and complex learning difficulties. The aim of this project was to include disabled young people in the national Olympiad and creatively explore the theme of sporting prowess. The results of the workshops were performed in Portsmouth Guildhall Square, the municipal centre of the city, for the general public as a celebration of the young people involved. The workshops involved making giant puppets out of found materials for their body parts, including rugby balls turned inside-out for heads and tennis and badminton rackets for legs and arms. They were built around a simple skeletal bamboo frame. These figures were roughly three metres in height and rather odd in appearance. The other activity I facilitated was making junk music using old plastic 
containers and tin cans to complement and accompany the puppet figures in their movements.

For the final show, after we had presented the work in the school, the group of disabled schoolchildren gathered with me in the square with the puppets and junk instruments. The two forms combined well in the performance space, and the dissonant sounds of the junk drums matched the giant puppet assemblages, fixed together with cable ties and tape. This approach to street puppetry was inspired by the visionary artist Peter Schumann of Bread and Puppet Theatre (Brecht 1988). We particularly took on the idea that Schumann describes: that street performance, if it is to work effectively, needs to be 'louder than traffic' (Schumann cited in Bell 2013: 273). As well as the large-scale 'loud' visual impact, the performance had some other distinguishing features. The ritualistic appearance of the rough figures paraded around the municipal space by the group, made up of young people from the school, staff and university students, combined with the loud aural impact of the junk drums, performed a transformation in the space of the square. The dissonant sounds of the junk drums with the image of the puppets animated by disabled youth transgressed the everyday usual function and civic coding of the square. The production of ideology in space and place through the experience of socio-cultural exchange is central to the interests of cultural geographer Cresswell. Our contravention relates to how he believes cultural activities can transgress spaces. Within In Place/Out of Place, he explores how spaces produce 'normal' values that develop the production of ideology within these boundaries (Creswell 1996: 21). Against this set of dominant values and ideologies, there is the possibility of resistance through acts of 
transgression. These acts of transgression lead towards breaking the experience of feeling 'in place' and the new ideological position of the 'out of place'.

In relation to this concept of transgression, the disability and performance scholar Petra Kuppers explores how disabled bodies can interact within public space and dominant normative values in her account of a project in Christchurch, New Zealand, after the tragic earthquakes in 2011. Kuppers suggests that there is the problem of reception when disabled bodies perform in public space, for 'these acts of theatre can always already be reincorporated into business as usual, with disabled actors seen as nonperforming guarantors of authenticity, sans sarcasm' (Kuppers 2015: 172). Within the experience of Sporting Giants, the puppets also challenged the process of framing in this way, and this issue of authenticity was also present. Kuppers clearly states how the body of the disabled performer is framed but also how disabled performers have the opportunity to reshape public civic space. Kuppers suggests there is the opportunity to challenge 'our public spaces, shaking them up again, a durational task, one we engage in again and again when we navigate how people look at our faces, our wheelchairs, our rags, our choices in how we self-present in public' (2015): 173). Kuppers' view relates to the way the disabled body was presented in the space of the municipal cityscape in Sporting Giants, but the presentation of bodies was troubled by the use of puppets. In Sporting Giants, the performer's presence is amplified and augmented by the puppet. Puppets extend the possibility for 'loud' impact in street performance, but when the puppeteer's body (in this example a disabled body) is very visible and present within the assemblage of elements, this creates a dynamic hybrid performance mode. This chimera of bodies in the public space both troubles and challenges ideas of otherness. The noise 
and street theatre in Sporting Giants did not inhabit a protest or activist format. The event instead was a warm disruption of the everyday that made the participants even more present in the space. In this event, the participant's otherness was not hidden, negated or normalized but was amplified by the junk puppets and junk music. This rather chaotic event had no real sense of narrative or obvious purpose. On reflection, the sense of otherness being celebrated was present, and in this way, the puppet was used as a method to explore otherness and transgression and to challenge pejorative assumptions about concepts of disability. Puppets open up strange spaces in urban contexts as they disrupt subject and object relations about things in spaces. Puppets in this process 'subjectify' the otherness of objects and the bodies that are manipulating the puppet. Through this dynamic process, the puppets and the manipulators are othered within the activity, but also positively amplified within the public space. One member of the public commented in the local press about how 'warm' the event had made them feel in the Guildhall Square. The aural and visual dissonance of the event changed the way this space was received and understood.

\section{Biopower and otherness}

The Sentient Spoon and the Sporting Giant puppets split apart object and subject relations by provoking audiences to reconsider relations between what is othered. Social or medical models of bodies do not appear to make sense in this pataphysical (Jarry et al. 1965) world ${ }^{1}$ of the puppet where normalizing categories break down in these examples. Even when the Sentient Spoon puppet appears dysfunctional as a theatrical object (because of his small scale), he still has the ability to transgress human notions of geographical space and 'live on' after his performance. The Sentient Spoon's surreal 
presence humorously provokes us to think beyond the unified ideas of embodiment.

Othering the body in this way valorizes differences and oddities. If we were to extend this playful approach to bodies and spaces, we might radically reconsider the way we construct our urban environments and social formations around bodies.

In relation to valorizing difference, influential puppet company Doo Cot? provoked audiences in their show Odd if You Dare (1995) to consider the puppet as a form to challenge normative identity politics, present transgressive images of deviance and explore queer culture. As Benjamin Gillespie suggests, theatrical materiality can be full of queer objects: 'By recasting the object as actor, the theatre (perhaps inadvertently) provides the space to enact queered reading practices that re-evaluate the ignored, underrated, incapacitated, and recalcitrant performances of humans and objects alike' (Gillespie, cited in Schweitzer and Zerdy 2014: 151).

In most of my practice, the oddity of the puppet, roughly constructed and crudely performed, enabled groups to play with creativity and also the role of identities. In this way, the puppet is not broken in my practice but instead breaks down the normalizing physical values around ideas about 'life'. In my applied puppetry practice, I have not radically changed this approach in reaction to different individual identities within community groups; in many ways, the inherent oddity of using performing objects allows me a form through which I can give space to individual identities and enable them to celebrate their own oddity and difference. The puppets and objects themselves do a lot of this work in the space of the workshop. When an inside-out rugby ball, in the case of Performing Giants, is a head and a spoon is sentient, then this topsy-turvy world accepts and celebrates all kinds of identities. 
Puppets can enable us to have the confidence to be odd, as the puppet is always other. The puppet as creative bridge also enables different subjectivities to create when the normative rules are troubled by puppet oddness.

Despite these positive uses of the puppet, there is also the negative side of puppetry when it is used to stereotype and actually enforce caricatures of identity. There are examples of this in history; for example, Nazi puppet troupes (Kamenetsky 1984) and population control campaigns in post-war India (Baird 1971). Even so, these stark examples of puppets - understood as part of Michel Foucault's concept of biopower (1998) - within this propaganda-style puppetry, still retain their oddity. Foucault suggests that the production of power and politics is linked to and focuses on the body and its life. Foucault's positioning of politics is a way of understanding how bodies are involved in applied puppetry. Puppeteers need to sensibly consider the way in which they include diverse identities in order to respect participants, as well as celebrating oddity. Foucault's perception of the body and power can be applied to the normative ableist context of contemporary society. This network of vibrant forces is troubled by the use of puppetry oddness through practice.

\section{Conclusion}

Biopower raises questions about the politics and ethics of applied puppetry as a practice in relation to the diverse identities of group members, involving how puppetry affects the bodies of the people involved as audience members or workshop participants, and involves them in processes. Biopower is exchanged and developed through the interactions between subjects, spaces, the puppet as object and the discourses used in the practice. These elements indicate the potential power of applied puppetry, and an 
attentiveness towards the interaction of these forces can inform effective practice.

Puppets are vibrant, uncanny and metaphorical objects, and this power is important to acknowledge when conducting applied puppetry in specific communities and workshop locations. Reading puppets and performing objects in relation to structures and systems of power is a method to critically reflect on the practice as one that affects the human through the more-than-human objects involved.

Over the years, puppetry has enabled me and fellow collaborators to work with a multifarious list of groups in community settings within the context of very particular systems of power. In the most effective examples, this work with puppets was not employing the puppet as some form of instrumentalized blunt tool, but instead, as a creative agent in the space unlocking individual participants' imaginings. The puppet respected in this way can become a great collaborator because of its inherent oddity, otherness and transgressive potential. Puppets open spaces for individuals to express their unique viewpoint and creativity without conforming to types, models or what is correct or appropriate. This practice respectfully includes objects and bodies in a celebration of life, troubling biopower and speaking beyond normative values. Taking these disruptive cocreators into coded social spaces has often developed into, in my experience, surprising experiences of community-based practice. My next project will be to explore how this disruptive creative potential can be employed when using puppets to suggest new ways of re-imaging and re-visioning our urban spaces through the development of a Puppet City. 


\section{References}

Baird, Bil (1971), Puppets and Population, New York: World Education.

Bass, Eric (2014), 'Myths of the puppet theater', https://howlround.com/myths-puppet-

theater. Accessed 6 April 2020.

Bell, John (2013), 'Louder than traffic: Bread and puppet parades', in J. Cohen-Cruz

(ed.), Radical Street Performance: An International Anthology, London:

Routledge, pp. 272-80.

Bennett, Jane (2009), Vibrant Matter: A Political Ecology of Things, Durham, NC: Duke University Press.

Bogost, Ian (2012), Alien Phenomenology, or, What It's Like to Be a Thing, London: University of Minnesota Press.

Brecht, Stefan (1988), Peter Schumann's Bread and Puppet Theatre, vols. 1 and 2, London: Methuen.

Corbyn, Zoë (2005), ‘An Introduction to Pataphysics', The Guardian, https://www.theguardian.com/culture/2005/dec/09/8. Accessed: 18th September 2018

Cresswell, Tim (1996), In Place/Out of Place: Geography, Ideology, and Transgression, London: University of Minnesota Press.

Foucault, Michel (1998), The History of Sexuality, London: Penguin.

Harman, Graham (2010), Towards Speculative Realism: Essays and Lectures, Winchester: John Hunt Publishing.

Heidegger, Martin (1995), Being and Time, London: Blackwell. 
Jarry, Alfred, Shattuck, Roger and Watson Taylor, Simon (1965), Selected Works of Alfred Jarry, London: Methuen.

Kamenetsky, Christa (1984), Children's Literature in Hitler's Germany: The Culture Policy of National Socialism, Athens: Ohio University Press.

Kuppers, Petra (2015), 'Disability performance in the streets: Art actions in post-quake Christchurch', The Drama Review, 59:1, pp. 166-73.

Latour, Bruno (1993), We Have Never Been Modern, London: Harvester Wheatsheaf.

Schneider, Rebecca (2003), 'Performance remains', Performance Research, 6:2, pp. 10008.

Schweitzer, Marlis and Zerdy, Joanne (2014), Performing Objects and Theatrical Things, London: Palgrave Macmillan.

Smith, Matt (2012), 'The politics of applied puppetry', in L. Koflin (ed.), The Power of the Puppet, Zagreb: UNIMA Croatia, pp. 79-86.

— (2014), 'Towards a definition of applied puppetry', in L. Koflin (ed.), Međunarodni znanstveni skup, Europske odrednice pojma lutke i stručno lutkarsko nazivlje - Zbornik radova, Osijek: Academy of Arts, University of Osijek, pp. 83-94.

(2018), 'Hand to hand: The dynamic situation of applied puppetry', in K.

Konania (ed.), Dolls and Puppets: Contemporaneity and Tradition, Warsaw: The Aleksander Zelwerowicz National Academy of Dramatic Art, pp. 40-45.

\section{Notes}

1. 'Pataphysics is the science of imaginary solutions' (Jarry et al. 1965): 22). A good guide to the idea of pataphysics is found in the Guardian article (Corbyn 2005). 
2. https://wepa.unima.org/en/doo-cot/. Accessed, 18th September 2018

Matt Smith has asserted their right under the Copyright, Designs and Patents Act, 1988, to be identified as the author of this work in the format that was submitted to Intellect Ltd. 
Figures 1 and 2: Sentient Spoon puppet, originally from The Generosity of Penguins (1995) by Lavinia Murray, 2019. Photography by Matt Smith.
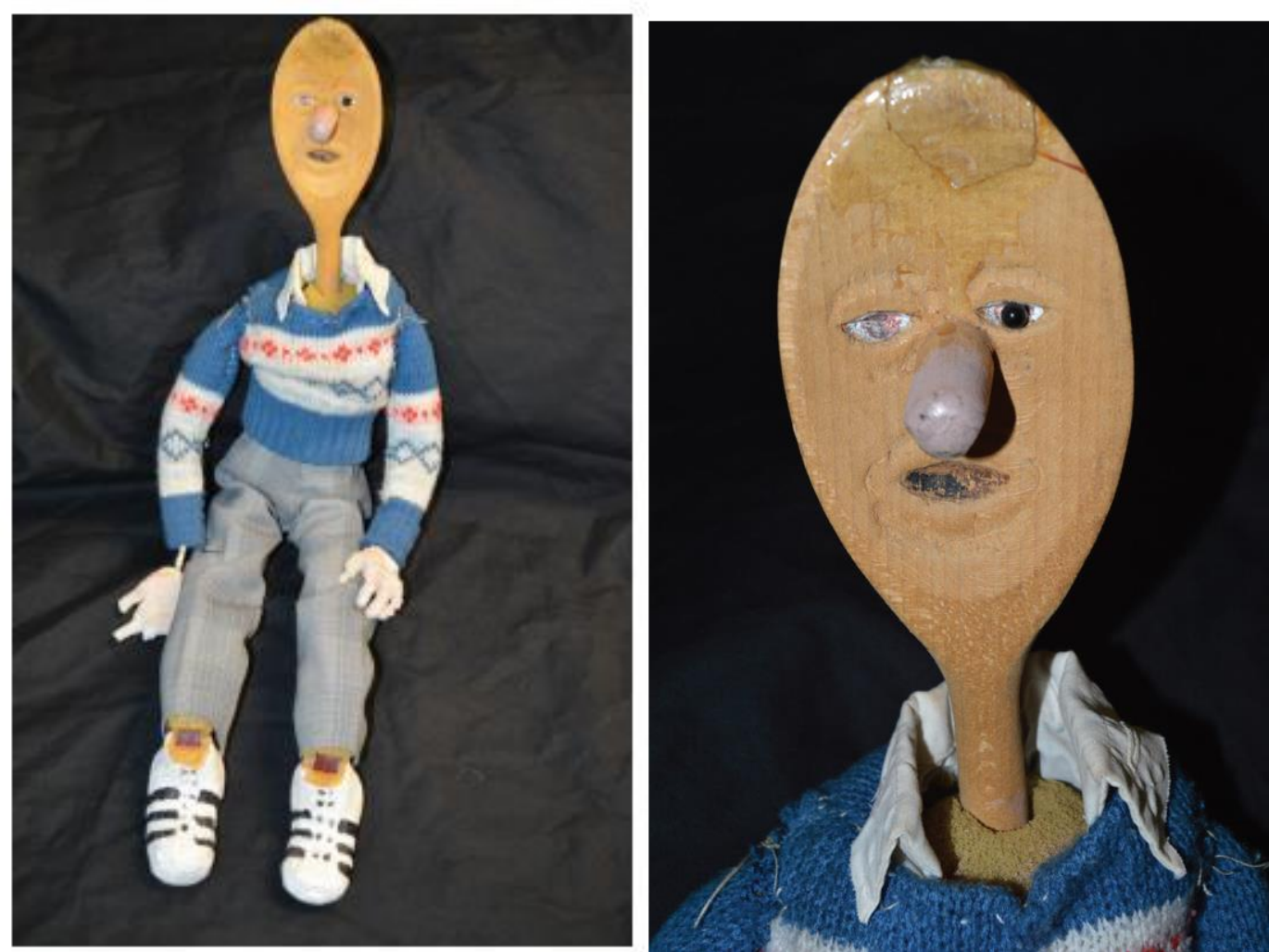